\title{
Kinetics of Graphitization of Cementite *
}

\author{
By Kohei Kubota** and Satoru Yamamoto***
}

\begin{abstract}
Dilatometric measurements were carried out during the first-stage graphitization of white cast irons. It has turned out that the data can not be analyzed consistently by the rate equations proposed by Johnson-Mehl or Austin-Rickett. A new type of rate equation, $\mathrm{Y}=1-\exp \left\{-\left(t / \tau_{1}\right)^{n_{1}}\left[1-e^{-\left(t / \tau_{2}\right)^{n_{2}}}\right]\right.$ $\left.\left[1-e^{-\left(t / \tau_{3}\right)^{n_{3}}}\right]^{-1}\right\}$ has been derived and proposed to interpret the data in terms of the following model: The rate of graphitization is controlled by the interfacial reaction by which cementite dissolves in the austenite, and the number of dissolving cementite particles increases with the increase of volume of voids in which graphite nodules are formed.
\end{abstract}

(Received April 9, 1984)

Keywords: kinetics, graphitization, cementite, new theory, experimental

\section{Introduction}

Many investigations on the kinetics of graphitization of cementite have been carried out. Table 1 is a list of the typical investigations. These investigations are based on the theories proposed by Johnson-Mehl, Avrami and Austin-Rickett ${ }^{(11)(12)}$. The conclusions on the rate-determining process for graphitization are overthrown two and three times. One of the reasons for this is that the theories cited above are rough approximations based upon a simplified model for graphitization of cementite. Therefore, the kinetic analysis of graphitization by such theories results in only partial and not full success. It is impossible to analyze the whole process of graphitization consistently. This situation is by no means satisfactory. For a comprehensive and consistent analysis of the whole process of graphitization, a new developement of rate equation is needed. In this report, a derivation of a new rate equation and its application to graphitization are presented.

* This paper was originally published in Japanese in J. Japan Inst. Metals, 46 (1982), 908.

** Graduate Student, Kyoto University, Kyoto 606, Japan. Present address: Railway Technical Research Institute, JNR, Tokyo 185, Japan.

*** Department of Metallurgy, Faculty of Engineering, Kyoto University, Kyoto 606, Japan.

\section{Experimental Procedure}

Cast irons used in this experiment were prepared from electrolytic iron of $99.976 \%$ purity, carbon of $99.998 \%$ purity, and metallic silicon of $98.6 \%$ purity. The element of sulphur (99\% purity), strontium (99\% purity) and magnesium (magcoke: coke saturated with $42 \% \mathrm{Mg}$ ), chromium (Fe-60.96\% Cr) were added to the melt. The charged composition and chemical composition of specimens are given in Table 2. Melting was carried out in air by the use of a kryptol furnace as follows. Fe and $C$ were charged into a graphite crucible which was kept at $1573-1633 \mathrm{~K}$, and $\mathrm{Si}$ was added at $1673 \mathrm{~K}$ after melting. The melt was kept for $900 \mathrm{~s}$ at $1723 \mathrm{~K}$ and cast into metal moulds. Just before casting, the elements of $\mathrm{S}, \mathrm{Sr}$ and $\mathrm{Mg}$ were aded to the melt in an inverted claygraphite crucible which was attached to a graphite rod and plunged into the melt. In the case of simultaneous addition of $\mathrm{Mg}$ and $\mathrm{Cr}$, Cr was first added just before casting, and the melt was stirred up and then $\mathrm{Mg}$ was plunged into the melt. The diameter of metal moulds was $8 \times 10^{-3} \mathrm{~m}$ for $\mathrm{Mg}$-treated specimens and $4.5 \times 10^{-2} \mathrm{~m}$ for the other specimens. In the case of the ingot $4.5 \times 10^{-2} \mathrm{~m}$ in diameter, specimens of a rectangular prism shape $8 \times 10^{-3} \mathrm{~m}$ wide, $8 \times 10^{-3} \mathrm{~m}$ high and $3 \times 10^{-2} \mathrm{~m}$ long were cut out from symmetric positions about the center of the ingot to avoid the central part for the purpose of eliminating the influence of segregation after the confirmation of 
Table 1 Results of analysis of graphitization by the Johnson-Mehl equation.

\begin{tabular}{|c|c|c|}
\hline $\begin{array}{l}\text { No. of } \\
\text { literature }\end{array}$ & Year & Results of analysis (rate-determining process) \\
\hline (1) & 1954 & Diffusion of $\mathrm{Fe}$ and $\mathrm{Si}$ \\
\hline (2) & 1956 & Diffusion of $\mathrm{C}$ \\
\hline (3) & 1956 & Growth of graphite, solution of cementite \\
\hline (4) & 1959 & Solution of cementite \\
\hline (5) & 1960 & $\begin{array}{l}\text { Solution of cementite or crystallization of graphite ( } \mathrm{Fe}-\mathrm{C} \text { alloy) } \\
\text { Crystallization of graphite ( } \mathrm{Fe}-\mathrm{C}-\mathrm{Co} \text { alloy) }\end{array}$ \\
\hline$(6)$ & 1960 & $\begin{array}{l}\text { Solution of cementite (High purity alloy) } \\
\text { Diffusion of } C \text { (Commercial alloy) }\end{array}$ \\
\hline$(7)$ & 1962 & Solution of cementite \\
\hline (8) & 1962 & Solution of cementite and diffusion of atoms \\
\hline (9) & 1965 & Solution of cementite \\
\hline$(10)$ & 1971 & $\begin{array}{l}\text { Diffusion of } \mathrm{Fe} \text { and } \mathrm{Si} \text { ( } \mathrm{Up} \text { to } 40 \% \text { completion of reaction) } \\
\text { Solution of cementite (After } 40 \% \text { completion of reaction) }\end{array}$ \\
\hline
\end{tabular}

Table 2 Chemical composition of specimens.

\begin{tabular}{|c|c|c|c|c|c|c|c|c|}
\hline \multirow{3}{*}{$\begin{array}{l}\begin{array}{l}\text { No. of } \\
\text { alloys }\end{array} \\
\text { SI-1 }\end{array}$} & \multicolumn{4}{|c|}{ Charged composition } & \multicolumn{4}{|c|}{ Chemical analysis } \\
\hline & \multirow{2}{*}{$\frac{C}{2.4}$} & \multirow{2}{*}{$\frac{\mathrm{Si}}{1.5}$} & \multicolumn{2}{|c|}{ Additional elements } & \multirow{2}{*}{$\frac{C}{2.35}$} & \multirow{2}{*}{$\frac{\mathrm{Si}}{1.71}$} & \multicolumn{2}{|c|}{ Additional elements } \\
\hline & & & - & - & & & - & - \\
\hline SI-2 & 2.4 & 1.2 & - & - & 2.32 & 1.22 & - & - \\
\hline SI-3 & 2.4 & 0.9 & - & - & 2.38 & 0.88 & - & - \\
\hline SI-4 & 2.4 & 0.6 & - & - & 2.32 & 0.60 & - & - \\
\hline SI-5 & 2.4 & 0.2 & - & - & 2.50 & 0.20 & - & - \\
\hline SI-6 & 2.4 & 0.0 & - & - & 2.39 & 0.00 & - & - \\
\hline$S-1$ & 2.4 & 1.1 & $0.2 \mathrm{~S}$ & - & 2.47 & 1.10 & $0.27 \mathrm{~S}$ & - \\
\hline S-2 & 2.4 & 1.1 & $0.0 \mathrm{~S}$ & - & 2.44 & 1.10 & $0.01 \mathrm{~S}$ & - \\
\hline MG-1 & 2.6 & - & $0.07 \mathrm{Mg}$ & - & 2.60 & - & $0.044 \mathrm{Mg}$ & - \\
\hline MG-2 & 3.9 & - & $0.07 \mathrm{Mg}$ & - & 3.93 & - & $0.068 \mathrm{Mg}$ & - \\
\hline MR-1 & 2.6 & - & $0.07 \mathrm{Mg}$ & $0.04 \mathrm{Cr}$ & 2.55 & - & $0.036 \mathrm{Mg}$ & $0.037 \mathrm{Cr}$ \\
\hline SR-1 & 2.4 & 1.1 & $0.01 \mathrm{Sr}$ & - & 2.40 & 1.10 & $0.0015 \mathrm{Sr}$ & - \\
\hline SII-1 & 2.4 & 0.6 & - & - & 2.35 & 0.65 & - & - \\
\hline SII-2 & 2.4 & 0.2 & - & - & 2.64 & 0.18 & - & - \\
\hline SII-3 & 2.4 & 0.0 & - & - & 2.61 & - & - & - \\
\hline
\end{tabular}

(mass \%)

sound white cast irons. In the case of the ingot $8 \times 10^{-3} \mathrm{~m}$ in diameter, specimens were cut out from the part of the same height from the bottom.

The expansions of specimens during annealing were measured to monitor the rate of graphitization. For the measurement, an autorecording differential thermal analyzer DT-2B equipped with a differential dilatometer made by Shimadzu was used. Specimens were kept under Ar-atmosphere and at a constant temperature within $\pm 0.3 \mathrm{~K}$ during measure- ment. Variation of temperature was measured with the precision of $0.1 \mathrm{~K}$ and the influence was corrected. Specimens SI-1 to SI-6 were rapidly heated and the others were heated at the rate of $0.17 \mathrm{~K} / \mathrm{s}$. It took about $0.3 \mathrm{ks}$ for rapid heating. Dilatation-annealing time curves obtained under the conditions mentioned above were treated as transformation curves of graphitization of cementite. 


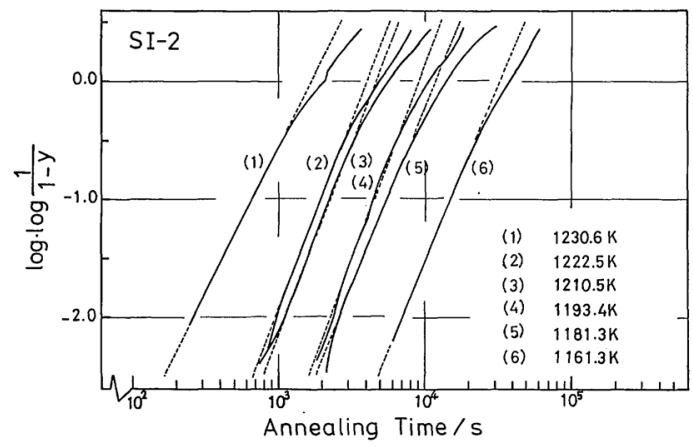

Fig. 1 Analysis of graphitization (SI-2) by Johnson-Mehl equation.

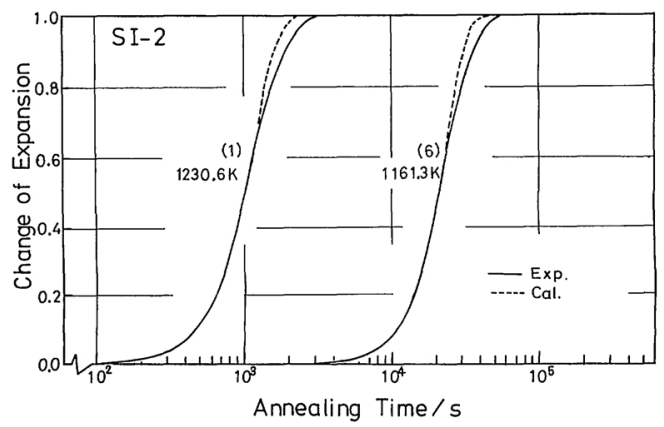

Fig. 2 Analysis of graphitization (SI-2) by Johnson-Mehl equation.

\section{Experimental Results and their Analysis}

\section{Analyses by Johnson-Mehl and Austin-Rickett equations}

Normalized transformation curves are given below by setting the whole expansions due to graphitization of cementite during annealing in unity.

If the transformation can be described by Johnson-Mehl equation (J-M equation), $Y=1-\exp \left\{-\left(k_{\mathrm{J}} t\right)^{n_{\mathrm{J}}}\right\}$, where $Y$ is the fraction transformed, $k_{\mathrm{J}}$ the reciprocal of the timeconstant, $t$ the time and $n_{\mathrm{J}}$ the time exponent, the plots of $\log \log (1 /(1-Y))$ against $\log t$ will be linear. Figure 1 shows this type of plotting of data in the case of specimen SI-2. Figure 2 shows $Y$ (fraction transformed) $-\log t$ curves calculated by using $n_{\mathrm{J}}$ and $k_{\mathrm{J}}$ determined from the analysis given in Fig. 1. Measured data deviate from the calculated curves to the longer time side in the latter half of the transformation process. For the comparison of the time exponent at various annealing temperatures, the value of $n_{\mathrm{J}}=2.47$ at 1230.6 $\mathrm{K}$ and $n_{\mathrm{J}}=2.95$ at $1161.3 \mathrm{~K}$ are obtained. Their interpretations based upon the J-M theory are as follows. At $1230.6 \mathrm{~K}$, nucleation of graphite occurs at a fixed rate and the diffusion of atoms controlls the growth process. On the other hand, at $1161.3 \mathrm{~K}$, the interfacial reaction controlls the growth of a fixed number of graphite particles. Thus the difference in annealing temperature by $70 \mathrm{~K}$ results in the quite different mechanism of graphitization of cementite. The transformation curves for $\mathrm{Mg}$ added specimens, MG-1, MG-2 and MR-1, are different from the others in shape. If the time exponent in the $\mathrm{J}-\mathrm{M}$ equation is determined so as to fit the data, the value of $n_{\mathrm{J}}$.changes with the annealing time. For example, in Fig. $3 n_{\mathrm{J}}$ changes like $2.5 \rightarrow 4 \rightarrow 2.5$. According to the $\mathrm{J}$ -

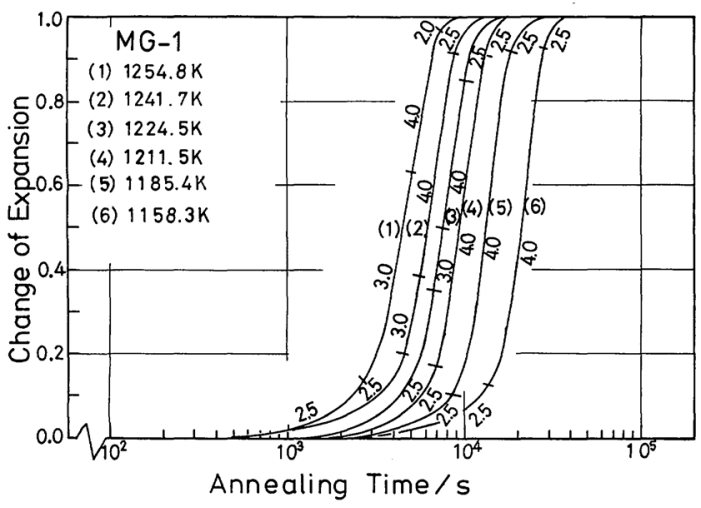

Fig. 3 Analysis of graphitization (MG-1) by JohnsonMehl equation.

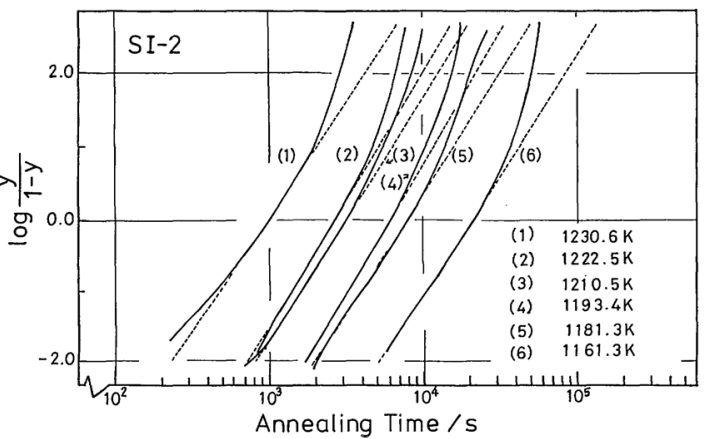

Fig. 4 Analysis of graphitization (SI-2) by AustinRickett equation. 


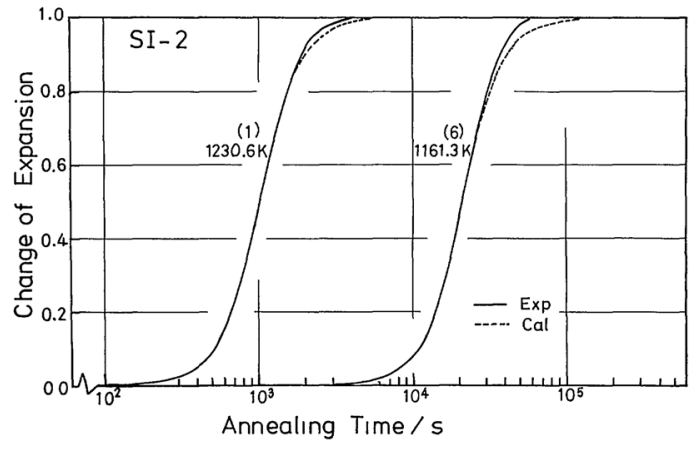

Fig. 5 Analysis of graphitization (SI-2) by AustinRickett equation.

$M$ theory, this means that at the initial and the final stage of the reaction, graphite nucleates at a fixed rate and the rate of their growth is determined by the diffusion of atoms and at the middle stage, graphite nucleates at a fixed rate and the interfacial reaction controlls the growth rate.

When the actual data deviate to the longer time side of the theoretical curve in the analysis based upon the J-M theory, they have occasionally been analyzed successfully by the equation of Austin-Rickett, $Y=\left(k_{\mathrm{A}} t\right)^{n_{\mathrm{A}}} /\{1+$ $\left.\left(k_{\mathrm{A}} t\right)^{n_{\mathrm{A}}}\right\}$. If the $\mathrm{A}-\mathrm{R}$ equation is applicable, the plotting of $\log \{Y /(1-Y)\}$ against $\log t$ will gives a straight line. The plotting of the data on the specimen SI-2 is shown in Fig. 4. The time exponent $n_{\mathrm{A}}$ and constant $k_{\mathrm{A}}$ are determined, if it is assumed that the data lie on a line. The so-determined transformation curves are given in Fig. 5. In the latter half of the transformation process, the data deviate to the shorter time side of the theoretical curve. In the same way as in the case of the J-M theory, the time exponent $n_{\mathrm{A}}$ determined at different annealing temperatures is compared; $n_{\mathrm{A}}=3.19$ at $1230.6 \mathrm{~K}$ and $n_{\mathrm{A}}=3.33$ at $1161.3 \mathrm{~K}$. The numerical value of $n_{\mathrm{A}}$ changes with the annealing temperature, although the magnitude is small compared with that in the case of the $\mathrm{J}-\mathrm{M}$ theory. Further, the mechanism of reaction can not be identified from these values of $n_{\mathrm{A}}$.

From these results, it is concluded that the $\mathrm{J}$ $\mathrm{M}$ theory or the A-R theory can not describe the whole process of graphitization of cementite consistently. If they are applied to the par- tial description, the mechanism may change entirely along with the temperature as well as the time lapse, and the physical meaning of the analyzed results becomes obscure. This is because the J-M equation and the A-R equation are derived based upon the oversimplified models of reactions and, therefore, the kinetic studies of the process of graphitization by the use of them inevitably result in the partial success and fail in the comprehensive and consistent analyses of the whole process. In order to take a step forward out of such an unsatisfactory stage, it is necessary to derive a new rate equation which faithfully reflects the complexity of real reactions.

\section{Derivation of a new rate equation and its application to the analyses}

(1) Derivation of a new rate equation

In this section a new rate equation is derived quite formally and its physical meaning is discussed later. Let us suppose a unit volume of parent phase and suppose that the volume of a new phase at time $t$ is $Y_{v}$ (that is, $Y_{v}$ is the fraction transformed). Let $G$ denote the migration rate of the interface between the parent and the product phases towards the direction normal to the interface. Then, the total rate of increase in the volume of the product phase is given by the equation,

$$
\frac{\mathrm{d} Y_{v}}{\mathrm{~d} t}=G S,
$$

where $S$ is the total area of the reacting interface between the parent and the product phases. Let us apply the concept of the extended volume $V_{\mathrm{e}}$ and extended area $S_{\mathrm{e}}$ originated by Johnson-Mehl and Avrami ${ }^{(11)-(13)}$ to get $S$ as a function of $Y_{v}$ and $t$. These are defined as the volume and area, respectively, when we suppose that all the regions already transformed continue to grow without colliding with one another and that nuclei continue to form in transformed as well as untransformed regions. In other word, $V_{\mathrm{e}}$ is the sum of the actual transformed volume and the "virtual" volume when we suppose as if all the regions already transformed are untransformed regions and there a new phase nucleates and continues to grow. The $V_{\mathrm{e}}$ and $S_{\mathrm{e}}$ thus defined are mutually 
related by the equation similar to the eq. (1)

$$
\frac{\mathrm{d} V_{\mathrm{e}}}{\mathrm{d} t}=G S_{\mathrm{e}} .
$$

When the new phase is distributed at random, the fraction of the surface area which does not belong to the region already transformed is equal to the volume fraction of the untransformed regions ${ }^{(11)-(13)}$. Namely

$$
S=\left(1-Y_{v}\right) S_{\mathrm{e}} \text {. }
$$

From the combination of eq. (1), (2) and (3), we get

$$
\frac{\mathrm{d} Y_{v}}{\mathrm{~d} V_{\mathrm{e}}}=1-Y_{v} .
$$

By separation of variables and integration, we obtain

$$
Y_{v}=1-e^{-V_{\mathrm{c}}} .
$$

Let us calculate the transformed volume at time $t$ when the transformation starts at time $t_{1}$. In the present experiment, we must examine a decomposition of plate-like cementite particles. Therefore, when cementite starts to decompose at time $t_{1}$, the transformed volume of cementite at time $t$ is given by $A G\left(t-t_{1}\right)$, where $A$ is the effective cross-sectional area of plate-like cementite and is assumed to be independent of time for simplicity. The number of cementite particles which dissolve between the time $t_{1}$ and $t_{1}+\mathrm{d} t_{1}$ is

$$
\mathrm{d} n=I\left(1-Y_{v}\right) \mathrm{d} t_{1},
$$

assuming that the rate of increase in the number of dissolving cementite particles per unit volume of parent phase is $I$. The number of virtual cementite particles which are assumed to dissolve in the regions already transformed is $I Y_{v} \mathrm{~d} t_{1}$. Therefore, the total number of dissolving cementite particles is, including this,

$$
\mathrm{d} n_{1}=I \mathrm{~d} t_{1} .
$$

Therefore, the extended volume at time $t$ is

$$
V_{\mathrm{e}}=A G \int_{0}^{t}\left(t-t_{1}\right) I \mathrm{~d} t_{1} .
$$

$Y_{v}$ is given as a function of $t$ by the combination of eqs. (5) and (8). Then, in the next place, the calculation will be carried out in some cases where the concrete expression of $I$ is given.

Firstly, if the rate of increase in the number of dissolving cementite particles, $I$, decreases exponentially and is given by the equation

$$
I=\frac{N_{0}}{\tau_{2}} \exp \left(-\frac{t}{\tau_{2}}\right)
$$

the number of cementite particles which are dissolving at time $t: N$ is given by

$$
N=N_{0}\left\{1-\exp -\left(\frac{t}{\tau_{2}}\right)\right\} \text {. }
$$

By the use of eqs. (8) and (9)

$$
\begin{aligned}
V_{\mathrm{e}} & =A G \frac{N_{0}}{\tau_{2}} \int_{0}^{t}\left(t-t_{1}\right) \exp \left(-\frac{t_{1}}{\tau_{2}}\right) \mathrm{d} t_{1} \\
& =A G N_{0}\left\{t+\tau_{2}\left(e^{-t / \tau_{2}}-1\right)\right\} .
\end{aligned}
$$

If $\tau_{2} \gg t$, the following equation is obtained.

$$
V_{\mathrm{e}}=\frac{A G N_{0}}{2} t\left\{1-e^{-\left(t / \tau_{2}\right)}\right\} \text {. }
$$

Therefore,

$$
\begin{aligned}
Y_{v} & =1-e^{-V_{\mathrm{e}}}=1-\exp \left\{-\frac{A G N_{0}}{2} t\left[1-e^{-\left(t / \tau_{2}\right)}\right]\right\} \\
& =1-\exp \left[-\frac{A G t}{2} \cdot N\right] \\
& =1-\exp \left\{-\left(\frac{t}{\tau_{1}}\right)\left[1-\exp -\left(\frac{t}{\tau_{2}}\right)\right]\right\}
\end{aligned}
$$

where

$$
\tau_{1}=\frac{2}{A G N_{0}}
$$

If $\tau_{2} \ll t$,

$$
V_{\mathrm{e}}=A G N_{0} t \text {. }
$$

Then

$$
Y=1-e^{-V_{\mathrm{e}}}=1-e^{-\left(t / \tau_{\mathrm{eff}}\right)},
$$

where

$$
\tau_{\text {eff }}=\frac{1}{A G N_{0}} .
$$

Secondly if we assume the following equation

$$
N=N_{0}\left\{1-\exp -\left(\frac{t}{\tau_{2}}\right)^{2}\right\},
$$




$$
I=\frac{2 N_{0}}{\tau_{2}}\left(\frac{t}{\tau_{2}}\right) \exp -\left(\frac{t}{\tau_{2}}\right)^{2},
$$

then an approximate calculation, under the condition $t \ll \tau_{2}$, results in

$$
\begin{aligned}
V_{\mathrm{e}} & =\frac{2 A G N_{0}}{\tau_{2}^{2}} \int_{0}^{t}\left(t-t_{1}\right) t_{1} \exp -\left(\frac{t_{1}}{\tau_{2}}\right)^{2} \mathrm{~d} t_{1} \\
& \doteqdot \frac{A G N_{0}}{3} t\left[1-\exp -\left(\frac{t}{\tau_{2}}\right)^{2}\right]
\end{aligned}
$$

Therefore,

$$
\begin{aligned}
Y_{v} & =1-e^{-V_{\mathrm{c}}} \\
& =1-\exp \left\{-\frac{A G N_{0}}{3} t\left[1-\exp -\left(\frac{t}{\tau_{2}}\right)^{2}\right]\right\} \\
& =1-\exp \left\{-\frac{A G t}{3} \cdot N\right\} \\
& =1-\exp \left\{-\left(\frac{t}{\tau_{1}}\right)\left[1-\exp -\left(\frac{t}{\tau_{2}}\right)^{2}\right]\right\} .
\end{aligned}
$$

Here

$$
\tau_{1}=\left(\frac{3}{A G N_{0}}\right) .
$$

Furthermore, let us consider the case, where the number of dissolving cementite particles is given by the product of two factors i.e.

$$
N=N_{0}\left(1-e^{-t / \tau_{2}}\right)\left(1-e^{-t / \tau_{3}}\right)^{-1} \text {. }
$$

The product of two factors means that the number of dissolving cementite particles is proportional to the probability of the occurrence of two independent events. As discussed later in more details, the eq. (22) is suitable for the description of the explosive increase in the number of dissolving cementite particles at the early stage of graphitization of cementite. In this case, the rate of increase in the number of dissolving cementite particles, I, becomes

$$
\begin{aligned}
I= & N_{0}\left[\frac{1}{\tau_{2}} e^{-t / \tau_{2}}\left(1-e^{-t / \tau_{3}}\right)\right. \\
& \left.-\frac{1}{\tau_{3}} e^{-t / \tau_{3}}\left(1-e^{-t / \tau_{2}}\right)\right] /\left(1-e^{-t / \tau_{3}}\right)^{2} .
\end{aligned}
$$

Then if $\tau_{2}, \tau_{3} \gg t$,

$$
V_{e}=A G N_{0} \int_{0}^{t}\left\{( t - t _ { 1 } ) \left[\frac{1}{\tau_{2}} e^{-t_{1} / \tau_{2}}\left(1-e^{-t_{1} / \tau_{3}}\right)\right.\right.
$$

$$
\begin{aligned}
& \left.\left.-\frac{1}{\tau_{3}} e^{-t_{1} / \tau_{3}}\left(1-e^{-t_{1} / \tau_{2}}\right)\right] /\left(1-e^{-t_{1} / \tau_{3}}\right)^{2}\right\} \mathrm{d} t_{1} \\
\doteqdot & A G N_{0} t\left(1-e^{-t / \tau_{2}}\right)\left(1-e^{-t / \tau_{3}}\right)^{-1} \\
& \times\left(1-e^{-\frac{1}{4}\left(\frac{1}{\tau_{3}}-\frac{1}{\tau_{2}}\right) t}\right) \\
= & A G t N_{\text {eff }},
\end{aligned}
$$

where $N_{\text {eff }}=N\left(1-e^{-1 / 4\left(1 / \tau_{3}-1 / \tau_{2}\right) t}\right)$ is the effective number of cementite particles i.e. $N$ multiplied by $\left\{1-e^{-1 / 4\left(1 / \tau_{3}-1 / \tau_{2}\right) t}\right\}$. Therefore,

$$
\begin{aligned}
Y= & 1-e^{-V_{\mathrm{e}}} \\
= & 1-\exp \left\{-A G t \cdot N_{\mathrm{eff}}\right\} \\
= & 1-\exp \left\{-\left(\frac{t}{\tau_{1}}\right) \cdot\left(1-e^{-\left(\frac{t}{\tau_{2}}\right)^{2}}\right)\right. \\
& \left.\times\left(1-e^{-t / \tau_{3}}\right)^{-1}\right\},
\end{aligned}
$$

where

$$
\tau_{1}=\left(\frac{1}{A G N_{0}}\right) .
$$

If $\tau_{2}, \tau_{3} \ll t$, then

$$
V_{\mathrm{e}}=A G N_{0} t
$$

and

$$
Y=1-e^{-V_{e}}=1-\exp -\left(\frac{t}{\tau_{1}}\right),
$$

where

$$
\tau_{1}=\left(\frac{1}{A G N_{0}}\right)
$$

If we continue to calculate in the same way, the following type of equation in general is obtained

$$
\begin{aligned}
Y_{v}= & 1-\exp \left\{-\left(\frac{t}{\tau_{1}}\right)\left[1-\exp -\left(\frac{t}{\tau_{2}}\right)^{n_{2}}\right]\right. \\
& \left.\times\left[1-\exp -\left(\frac{t}{\tau_{3}}\right)^{n_{3}}\right]^{-1}\right\} \\
= & 1-\exp \left\{-\left(\frac{t}{\tau_{1}}\right) \cdot N\right\},
\end{aligned}
$$

where $n_{2}$ and $n_{3}$ are the effective time exponents, the $\tau_{1}, \tau_{2}$ and $\tau_{3}$ are the effective time constants and $N$ is the effective number of cementite particles dissolving at time $t$, and the shape of cementite is assumed to be plate-like 
and to be dissolved by the interfacial reaction.

The eq. (30) can be held only when the shape of the transformed region is plate-like. If its shape is not plate-like but spherical, the volume of the transformed region at time $t$ which started to transform at time $t_{1}$ is $4 \pi G^{3}\left(t-t_{1}\right)^{3} / 3$. The equation cooresponding to the eq. (8) becomes

$$
V_{\mathrm{e}}=\frac{4}{3} \pi G^{3} \int_{0}^{t}\left(t-t_{1}\right)^{3} \cdot I d t_{1} .
$$

If $I$ is given by the eq. (9),

$$
\begin{aligned}
Y_{v} & =1-e^{-V_{e}} \\
& =1-\exp \left\{-\left(\frac{t}{\tau_{1}}\right)^{3}\left[1-\exp -\left(\frac{t}{\tau_{2}}\right)\right]\right\},
\end{aligned}
$$

where

$$
\tau_{1}=\left(\frac{3}{\pi N_{0} G^{3}}\right)^{1 / 3} .
$$

Thus the eq. (30) can be rewritten in a more generalized form depending on the change in the shape of transformed region and on the change in the rate of increase in the number of transforming particles.

$$
\begin{aligned}
Y_{v}= & 1-e^{-V_{\mathrm{e}}} \\
= & 1-\exp \left\{-\left(\frac{t}{\tau_{1}}\right)^{n_{1}}\left[1-\exp -\left(\frac{t}{\tau_{2}}\right)^{n_{2}}\right]\right. \\
& \left.\times\left[1-\exp -\left(\frac{t}{\tau_{3}}\right)^{n_{3}}\right]^{-1}\right\} \\
= & 1-\exp \left\{-\left(\frac{t}{\tau_{1}}\right)^{n_{1}} \cdot N\right\} .
\end{aligned}
$$

The eq. (34) can be regarded as the generalized form of the J-M equation, because this equation is reduced to the J-M equation if the term $N$ is expanded in Taylor's series under the condition $t \ll \tau_{2}, \tau_{3}$.

(2) Application of the new rate equation

The new rate eq. (34) is applied to the analysis of the rate of graphitization of cementite. Firstly, the result of analysis by the new equation, of the data of specimen SI-2, which have already been analyzed in the previous section by the use of the J-M equation and A-R equation, is shown in Fig. 6. A much better

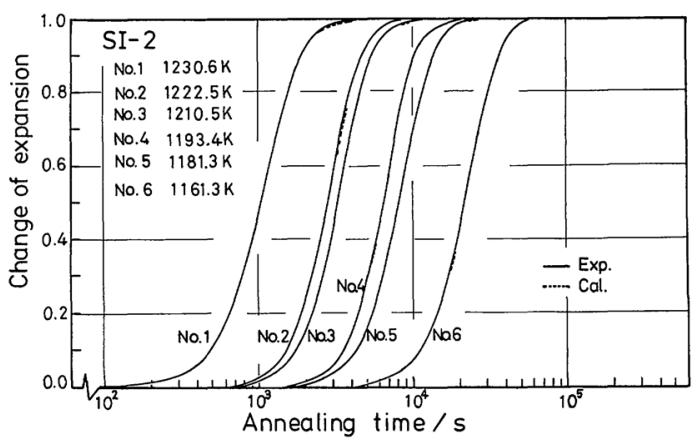

Fig. 6 Analysis of graphitization (SI-2) by new equation.

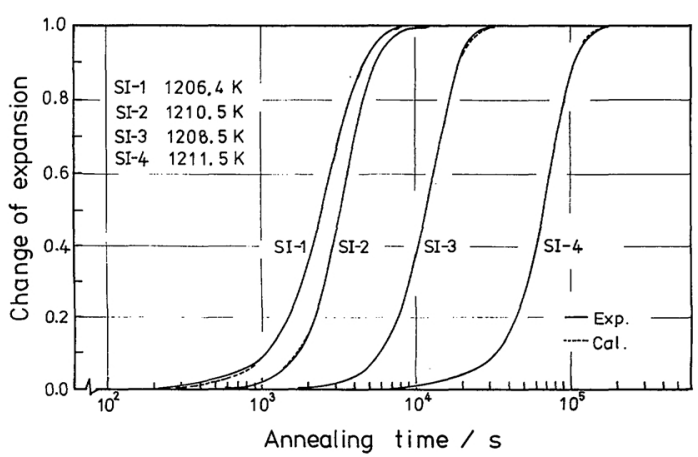

Fig. 7 Analysis of graphitization (SI-1-SI-4) by new equation.

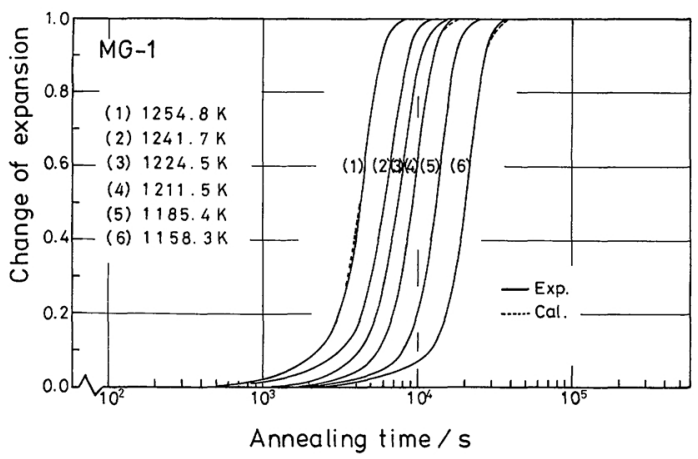

Fig. 8 Analysis of graphitization (MG-1) by new equation.

agreement with data is obtained in comparison with the analyses by the J-M and A-R equations, and furthermore a consistent analysis by the same equation is possible irrespective of the annealing temperature. A similar result of analysis is given in Fig. 7 by changing the Si content. Graphitization is slowed with decreasing Si content. In the specimens with $0.2 \%$ or 
Table 3 Results of analysis of graphitization (SI-1) by new equation.

SI-1

\begin{tabular}{lcccccc}
\hline \hline $\begin{array}{c}\text { Annealing } \\
\text { temperature (K) }\end{array}$ & 1232.6 & 1217.5 & 1206.4 & 1195.4 & 1181.3 & 1159.3 \\
\hline$n_{1}$ & 1.0 & 1.0 & 1.0 & 1.0 & 1.0 & 1.0 \\
$\tau_{1}(\mathrm{ks})$ & 0.84 & 1.44 & 1.50 & 2.40 & 4.56 & 13.20 \\
$n_{2}$ & 1.25 & 1.5 & 1.5 & 1.8 & 2.1 & 1.1 \\
$\tau_{2}(\mathrm{ks})$ & 1.15 & 2.50 & 3.67 & 4.98 & 10.75 & 82.68 \\
$n_{3}$ & 0.0 & 0.0 & 0.0 & 0.0 & 0.0 & 0.0 \\
$\tau_{3}(\mathrm{ks})$ & $\infty$ & $\infty$ & $\infty$ & $\infty$ & $\infty$ & $\infty$ \\
\hline \hline & $y=1-\exp \left[-\left(\frac{t}{\tau_{1}}\right)^{n_{1}}\left\{1-\exp -\left(\frac{t}{\tau_{2}}\right)^{n_{2}}\right\} \cdot\left\{1-\exp -\left(\frac{t}{\tau_{3}}\right)^{n_{3}}\right\}^{-1}\right]$ & &
\end{tabular}

SI-2

Table 4 Results of analysis of graphitization (SI-2) by new equation.

\begin{tabular}{lcccccc}
\hline \hline $\begin{array}{c}\text { Annealing } \\
\text { temperature }(\mathrm{K})\end{array}$ & 1230.6 & 1222.5 & 1210.5 & 1193.4 & 1181.3 & 1161.3 \\
\hline$n_{1}$ & 1.0 & 1.0 & 1.0 & 1.0 & 1.0 & 1.0 \\
$\tau_{1}(\mathrm{ks})$ & 0.68 & 1.44 & 1.80 & 3.30 & 3.84 & 8.40 \\
$n_{2}$ & 1.6 & 2.0 & 2.0 & 2.2 & 1.85 & 1.8 \\
$\tau_{2}(\mathrm{ks})$ & 1.51 & 4.34 & 4.77 & 9.37 & 13.92 & 43.30 \\
$n_{3}$ & 0.0 & 0.0 & 0.0 & 0.0 & 0.0 & 0.0 \\
$\tau_{3}(\mathrm{ks})$ & $\infty$ & $\infty$ & $\infty$ & $\infty$ & $\infty$ \\
\hline \hline
\end{tabular}

Table 5 Results of analysis of graphitization (SI-3) by new equation.

SI-3

\begin{tabular}{|c|c|c|c|c|c|}
\hline $\begin{array}{l}\text { Annealing } \\
\text { temperature }(\mathrm{K})\end{array}$ & 1232.6 & 1221.5 & 1208.5 & 1194.4 & 1179.3 \\
\hline$n_{1}$ & 1.0 & 1.0 & 1.0 & 1.0 & 1.0 \\
\hline$\tau_{1}(\mathrm{ks})$ & 2.77 & 4.08 & 5.28 & 7.86 & 17.34 \\
\hline$n_{2}$ & 2.0 & 1.8 & 1.9 & 1.9 & 2.15 \\
\hline$\tau_{2}(\mathrm{ks})$ & 7.16 & 9.79 & 19.73 & 32.83 & 57.90 \\
\hline$n_{3}$ & 0.0 & 0.0 & 0.0 & 0.0 & 0.0 \\
\hline$\tau_{3}(\mathrm{ks})$ & $\infty$ & $\infty$ & $\infty$ & $\infty$ & $\infty$ \\
\hline
\end{tabular}

no additional $\mathrm{Si}$, graphitization did not start during annealing at $1273.2 \mathrm{~K}$ for $300 \mathrm{ks}$. These analytical results are summarized in Table 3 . Secondly, similar results of analyses of other specimens under other conditions are shown in Fig. 8 and in Table 4 to Table 13. The parameters such as $n_{1}, n_{2}, n_{3}, \tau_{1}, \tau_{2}$ and $\tau_{3}$ are determined by a curve fitting method. The following are known from these results.
(1) The process of graphitization of cementite can be analyzed by the rate equation,

$$
\begin{aligned}
Y= & 1-\exp \left\{-\left(\frac{t}{\tau_{1}}\right)^{n_{1}}\left[1-\exp -\left(\frac{t}{\tau_{2}}\right)^{n_{2}}\right]\right. \\
& \left.\times\left[1-\exp -\left(\frac{t}{\tau_{3}}\right)^{n_{3}}\right]^{-1}\right\} .
\end{aligned}
$$

(2) The time exponent $n_{1}=1.0$. This value 
remains constant irrespective of annealing temperature, Si content and the presence of additional elements. The time constant $\tau_{1}$ (i) shows a temperature dependence, i.e. the

Table 6 Results of analysis of graphitization (SI-4) by new equation.

SI-4

\begin{tabular}{lcccc}
\hline \hline $\begin{array}{c}\text { Annealing } \\
\text { tempera- } \\
\text { ture (K) }\end{array}$ & 1232.6 & 1221.5 & 1211.5 & 1194.4 \\
\hline$n_{1}$ & 1.0 & 1.0 & 1.0 & 1.0 \\
$\tau_{1}(\mathrm{ks})$ & 14.40 & 18.00 & 25.20 & 36.00 \\
$n_{2}$ & 1.6 & 1.5 & 2.0 & 1.1 \\
$\tau_{2}(\mathrm{ks})$ & 153.70 & 106.92 & 118.20 & 256.20 \\
$n_{3}$ & 1.5 & 1.5 & 2.0 & 1.0 \\
$\tau_{3}(\mathrm{ks})$ & 15.02 & 23.32 & 20.52 & 24.52 \\
\hline \hline
\end{tabular}

$$
\begin{aligned}
y= & 1-\exp \left[-\left(\frac{t}{\tau_{1}}\right)^{n_{1}}\left\{1-\exp -\left(\frac{t}{\tau_{2}}\right)^{n_{2}}\right\}\right. \\
& \left.\cdot\left\{1-\exp -\left(\frac{t}{\tau_{3}}\right)^{n_{3}}\right\}^{-1}\right]
\end{aligned}
$$

Table 7 Results of analysis of graphitization (S-1) by new equation.

S-1

\begin{tabular}{lcccc}
\hline \hline $\begin{array}{c}\text { Annealing } \\
\text { tempera- } \\
\text { ture (K) }\end{array}$ & 1283.0 & 1271.9 & 1261.8 & 1253.8 \\
\hline$n_{1}$ & 1.0 & 1.0 & 1.0 & 1.0 \\
$\tau_{1}(\mathrm{ks})$ & 1.49 & 2.40 & 3.24 & 3.96 \\
$n_{2}$ & 1.25 & 1.85 & 1.8 & 1.7 \\
$\tau_{2}(\mathrm{ks})$ & 2.96 & 7.07 & 15.59 & 19.90 \\
$n_{3}$ & 0.0 & 0.0 & 0.0 & 0.0 \\
$\tau_{3}(\mathrm{ks})$ & $\infty$ & $\infty$ & $\infty$ & $\infty$ \\
\hline \hline
\end{tabular}

$$
\begin{aligned}
y= & 1-\exp \left[-\left(\frac{t}{\tau_{1}}\right)^{n_{1}}\left\{1-\exp -\left(\frac{t}{\tau_{2}}\right)^{n_{2}}\right\}\right. \\
& \left.\cdot\left\{1-\exp -\left(\frac{t}{\tau_{3}}\right)^{n_{3}}\right\}^{-1}\right]
\end{aligned}
$$

lower the temperature, the larger the value of $\tau_{1}$, (ii) depends on the presence of additional elements, i.e., additional $\mathrm{Cr}$ or $\mathrm{S}$ increases the value and $\mathrm{Si}, \mathrm{Mg}$ and $\mathrm{Sr}$ decrease it, and (iii) increases with increasing $\mathrm{C}$ content.

(3) The time exponent $n_{2}$ ranges from 1.0 to 2.2 . The mean value is about 1.5 . However, it fluctuates between 2.8 and 3.3 for the specimen MG-1 and between 1.5 and 3.5 for the specimen SR-1. The time constant $\tau_{2}$ has also a temperature dependence and generally increases with decreasing annealing temperature.

(4) The term including the time exponent $n_{3}$ has a remarkable effect in the specimens SI4, SR-1, MG-1 and MR-1. However, the effect becomes negligibly small when the specimens are pre-annealed. The value of $n_{3}$ is usually 0.8 to 2.0 but 2.1 to 3.0 for the specimen MG-1 and 1.5 to 2.5 for the specimen SR-1. The time

Table 8 Results of analysis of graphitization (S-2) by new equation.

S-2

\begin{tabular}{lllll}
\hline \hline $\begin{array}{c}\text { Annealing } \\
\text { tempera- } \\
\text { ture (K) }\end{array}$ & 1269.9 & 1251.7 & 1230.6 & 1209.5 \\
\hline$n_{1}$ & 1.0 & 1.0 & 1.0 & 1.0 \\
$\tau_{1}(\mathrm{ks})$ & 0.43 & 0.80 & 1.62 & 3.36 \\
$n_{2}$ & 1.8 & 2.0 & 2.1 & 1.8 \\
$\tau_{2}(\mathrm{ks})$ & 0.82 & 1.69 & 3.64 & 16.24 \\
$n_{3}$ & 0.0 & 0.0 & 0.0 & 0.0 \\
$\tau_{3}(\mathrm{ks})$ & $\infty$ & $\infty$ & $\infty$ & $\infty$ \\
\hline \hline
\end{tabular}

$$
\begin{aligned}
y= & 1-\exp \left[-\left(\frac{t}{\tau_{1}}\right)^{n_{1}}\left\{1-\exp -\left(\frac{t}{\tau_{2}}\right)^{n_{2}}\right\}\right. \\
& \left.\cdot\left\{1-\exp -\left(\frac{t}{\tau_{3}}\right)^{n_{3}}\right\}^{-1}\right]
\end{aligned}
$$

MG-1

Table 9 Results of analysis of graphitization (MG-1) by new equation.

\begin{tabular}{llccccc}
\hline \hline $\begin{array}{c}\text { Annealing } \\
\text { temperature (K) }\end{array}$ & 1254.8 & 1241.7 & 1224.5 & 1211.5 & 1185.4 & 1158.3 \\
\hline$n_{1}$ & 1.0 & 1.0 & 1.0 & 1.0 & 1.0 & 1.0 \\
$\tau_{1}(\mathrm{ks})$ & 1.50 & 2.16 & 2.76 & 3.36 & 4.08 & 6.54 \\
$n_{2}$ & 3.0 & 2.8 & 3.0 & 3.3 & 3.3 & 3.3 \\
$\tau_{2}(\mathrm{ks})$ & 6.58 & 9.74 & 11.46 & 13.87 & 20.78 & 32.32 \\
$n_{3}$ & 3.0 & 2.5 & 2.1 & 3.0 & 3.0 & 3.0 \\
$\tau_{3}(\mathrm{ks})$ & 2.23 & 3.35 & 3.91 & 4.60 & 6.77 & 12.26 \\
\hline \hline
\end{tabular}

$$
y=1-\exp \left[-\left(\frac{t}{\tau_{1}}\right)^{n_{1}}\left\{1-\exp -\left(\frac{t}{\tau_{2}}\right)^{n_{2}}\right\} \cdot\left\{1-\exp -\left(\frac{t}{\tau_{3}}\right)^{n_{3}}\right\}^{-1}\right]
$$


MG-2

Table 10 Results of analysis of graphitization (MG-2) by new equation.

\begin{tabular}{lccccc}
\hline \hline $\begin{array}{c}\text { Annealing } \\
\text { temperature (K) }\end{array}$ & 1258.8 & 1236.6 & 1208.5 & 1182.3 & 1161.3 \\
\hline$n_{1}$ & 1.0 & 1.0 & 1.0 & 1.0 & 1.0 \\
$\tau_{1}(\mathrm{ks})$ & 2.76 & 5.28 & 6.60 & 10.80 & 17.70 \\
$n_{2}$ & 1.1 & 1.0 & 1.0 & 1.5 & 1.6 \\
$\tau_{2}(\mathrm{ks})$ & 13.17 & 9.58 & 28.20 & 40.80 & 46.44 \\
$n_{3}$ & 1.1 & 0.8 & 1.0 & 1.5 & 1.5 \\
$\tau_{3}(\mathrm{ks})$ & 1.66 & 1.34 & 6.00 & 12.36 & 14.88 \\
\hline \hline
\end{tabular}

$$
y=1-\exp \left[-\left(\frac{t}{\tau_{1}}\right)^{n_{1}}\left\{1-\exp -\left(\frac{t}{\tau_{2}}\right)^{n_{2}}\right\} \cdot\left\{1-\exp -\left(\frac{t}{\tau_{3}}\right)^{n_{3}}\right\}^{-1}\right]
$$

Table 11 Results of analysis of graphitization (MR-1) by new equation.

MR-1

\begin{tabular}{lcccc}
\hline \hline $\begin{array}{c}\text { Annealing } \\
\text { tempera- } \\
\text { ture (K) }\end{array}$ & 1335.7 & 1280.0 & 1248.7 & 1214.5 \\
\hline$n_{1}$ & 1.0 & 1.0 & 1.0 & 1.0 \\
$\tau_{1}(\mathrm{ks})$ & 10.80 & 25.20 & 42.00 & 54.00 \\
$n_{2}$ & 1.4 & 1.3 & 1.3 & 1.3 \\
$\tau_{2}(\mathrm{ks})$ & 23.58 & 41.70 & 114.42 & 169.08 \\
$n_{3}$ & 0.0 & 1.0 & 1.0 & 1.0 \\
$\tau_{3}(\mathrm{ks})$ & $\infty$ & 9.34 & 27.30 & 19.85 \\
\hline \hline
\end{tabular}

$$
\begin{aligned}
y= & 1-\exp \left[-\left(\frac{t}{\tau_{1}}\right)^{n_{1}}\left\{1-\exp -\left(\frac{t}{\tau_{2}}\right)^{n_{2}}\right\}\right. \\
& \left.\cdot\left\{1-\exp -\left(\frac{t}{\tau_{3}}\right)^{n_{3}}\right\}^{-1}\right]
\end{aligned}
$$

constant $\tau_{3}$ also has a temperature dependence and increases as the temperature decreases.

\section{Discussion}

In the previous section, the process of graphitization of cementite has been analyzed based upon the rate equation,

$$
\begin{aligned}
Y= & 1-\exp \left\{-\left(\frac{t}{\tau_{1}}\right)^{n_{1}}\left[1-\exp -\left(\frac{t}{\tau_{2}}\right)^{n_{2}}\right]\right. \\
& \left.\times\left[1-\exp -\left(\frac{t}{\tau_{3}}\right)^{n_{3}}\right]^{-1}\right\},
\end{aligned}
$$

and the time exponents $n_{1}, n_{2}$ and $n_{3}$, and the time constants $\tau_{1}, \tau_{2}$ and $\tau_{3}$ have been determined. From these results, the rate equation can be summarized in the following way, reflecting the mechanism of graphitization.
Table 12 Results of analysis of graphitization (MRP-1) by new equation. MRP-1: Preannealing (MR-1) $108 \mathrm{ks}$ at $673 \mathrm{~K}$.

MRP-1 (MR-1 673 K 108 ks preannealing)

\begin{tabular}{lcc}
\hline \hline $\begin{array}{c}\text { Annealing } \\
\text { temperature }(\mathrm{K})\end{array}$ & 1282.0 & 1228.6 \\
\hline$n_{1}$ & 1.0 & 1.0 \\
$\tau_{1}(\mathrm{ks})$ & 18.00 & 32.40 \\
$n_{2}$ & 1.5 & 1.5 \\
$\tau_{2}(\mathrm{ks})$ & 49.68 & 150.48 \\
$n_{3}$ & 0.0 & 0.0 \\
$\tau_{3}(\mathrm{ks})$ & $\infty$ & $\infty$ \\
\hline \hline
\end{tabular}

$$
\begin{aligned}
y= & 1-\exp \left[-\left(\frac{t}{\tau_{1}}\right)^{n_{1}}\left\{1-\exp -\left(\frac{t}{\tau_{2}}\right)^{n_{2}}\right\}\right. \\
& \left.\cdot\left\{1-\exp -\left(\frac{t}{\tau_{3}}\right)^{n_{3}}\right\}^{-1}\right]
\end{aligned}
$$

$$
Y=1-\exp \{\underbrace{\left.-\left(\frac{t}{\tau_{1}}\right)^{1.0} \cdot N\right\}}_{1 \text { st term }},
$$

where

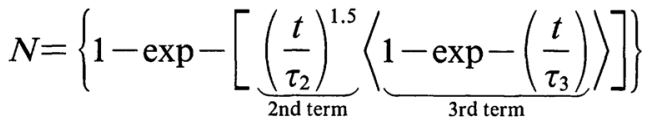

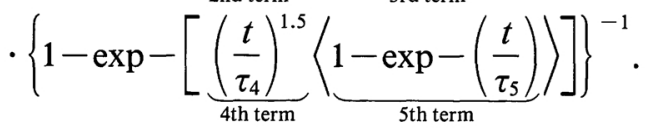

The physical meaning of eqs. (35) and (36) will be discussed in the following. Its method is based upon the examinations in which term from 1 st term to 5 th term, the effects of the change in annealing temperature and compositions of alloys and the effects of additional elements may appear, upon the examinations of the 
SR-1

Table 13 Results of analysis of graphitization (SR-1) by new equation.

\begin{tabular}{llccccc}
\hline \hline $\begin{array}{c}\text { Annealing } \\
\text { temperature }(\mathrm{K})\end{array}$ & 1261.8 & 1251.7 & 1228.6 & 1214.5 & 1193.4 & 1181.3 \\
\hline$n_{1}$ & 1.0 & 1.0 & 1.0 & 1.0 & 1.0 & 1.0 \\
$\tau_{1}(\mathrm{ks})$ & 1.08 & 1.56 & 2.94 & 5.28 & 9.90 & 14.40 \\
$n_{2}$ & 1.5 & 2.0 & 3.0 & 3.5 & 3.0 & 3.0 \\
$\tau_{2}(\mathrm{ks})$ & 4.56 & 7.74 & 16.20 & 29.10 & 59.16 & 68.10 \\
$n_{3}$ & 1.5 & 1.5 & 2.5 & 2.5 & 2.5 & 2.5 \\
$\tau_{3}(\mathrm{ks})$ & 1.11 & 2.40 & 8.52 & 17.88 & 30.00 & 35.40 \\
\hline \hline & $y=1-\exp \left[-\left(\frac{t}{\tau_{1}}\right)^{n_{1}}\left\{1-\exp -\left(\frac{t}{\tau_{2}}\right)^{n_{2}}\right\} \cdot\left\{1-\exp -\left(\frac{t}{\tau_{3}}\right)^{n_{3}}\right\}^{-1}\right]$
\end{tabular}

correspondence between the terms and metallographic informations and further upon the examinations by the use of the results of investigations in the past and every kind of knowledge and theory. The most probable conclusion will be mentioned in the next place.

Firstly, the first term in the above equation seems to correspond to the dissolution of cementite by the interfacial reaction. The reason is that the value of $n_{1}$ becomes 1.0 when the shape of cementite is plate-like and cementite dissolves by the interfacial reaction. It has been confirmed by metallographic observations that cementite is plate-like with the clear interface with austenite. This is consistent to the dissolution of cementite by the interfacial reaction. The correspondence of the first term to the dissolution of cementite is also supported by the facts that the time constant $\tau_{1}$ (a parameter for the stability of cementite) is increased in magnitude by the addition of $\mathrm{Cr}$ or $\mathrm{S}$ which stabilizes cementite and is decreased by the addition of $\mathrm{Si}, \mathrm{Mg}$ or $\mathrm{Sr}$ which makes cementite unstable. Based upon such an explanation of the first term, it is naturally understood that the time exponent $n_{1}$ is maintained unchanged (i.e. $n_{1}=1.0$ ) irrespective of annealing temperature, Si content and other additional elements and that the time constant has a temperature dependence and increases with the decrease in the annealing temperature. The activation energy calculated from the temperature dependence of $\tau_{1}$ is $386 \mathrm{~kJ} / \mathrm{mol}$ $(=4 \mathrm{eV})$ in the specimens SI-1 to SI-4, S-1, S-2 and SR-2 and this is nearly the same as the value reported previously when the solution of cementite is the rate-determining process ${ }^{(14)(15)}$.
The number of dissolving cementite particles, $N$, is described by the product of two terms bracketed by \{\} . This means that these two events are mutually independent and that the number of dissolving cementite particles is determined by the product of the probability of the occurrence of the two independent events. To determine them, the following five metallographic observations ${ }^{(15)-(21)}$ must be taken into consideration. (1) When cementite decomposes, $\mathrm{C}$ atoms from the cementite deposit and crystallize as graphite. (2) For the formation of graphite, $\mathrm{Fe}$ atoms must be removed by the diffusion away from the region. (3) If voids are present prior to graphitization, graphite is formed in the voids. (4) These voids are frozen and introduced during solidification of cast irons, when elements with low boiling points such as $\mathrm{Mg}$ and $\mathrm{Sr}$ are added. (5) Voids introduced during solidification will be annihilated thereafter during annealing.

From the considerations of these facts, it seems that among the two equations in bracket \{\} , the former (including 2nd and 3rd terms) stands for the formation reaction of spherical voids for the formation of graphite by the diffusion of $\mathrm{Fe}$ atoms and the latter (including 4th and 5th terms) stands for the annihilation reaction of voids pre-existent by the diffusion of vacancies (diffusion of $\mathrm{Fe}$ atoms to the opposite direction). It is confirmed by the following derivation that these reactions can be expressed by eq. (36).

The phenomenon of formation (annihilation) of an infinite number of voids may be treated statistically. Then, let us assume that 
the number of voids formed (annihilated) at time $t$ is given by the equation,

$$
N=N_{0}\left\{1-\exp -\left(\frac{t}{\tau_{3}}\right)\right\},
$$

and the rate of formation (annihilation) is given by

$$
I=\frac{\mathrm{d} N}{\mathrm{~d} t}=\frac{N_{0}}{\tau_{3}} \exp -\left(\frac{t}{\tau_{3}}\right) .
$$

On the other hand, the volume of the void at time $t$ which started to be formed (annihilated) at time $t_{1}$ is $4 \pi D^{3 / 2}\left(t-t_{1}\right)^{3 / 2} / 3$, as the diffusion distance $R$ at time $t$ is roughly given by

$R=\sqrt{D t} \quad(D:$ diffusion coefficient $)$.

Therefore, the extended volume of voids $V_{\mathrm{e}}$ is under the condition $t \ll \tau_{3}$

$$
\begin{aligned}
V_{\mathrm{e}} & =\frac{4}{3} \pi \frac{N_{0}}{\tau_{3}} D^{3 / 2} \int_{0}^{t}\left(t-t_{1}\right)^{3 / 2} \exp -\left(\frac{t_{1}}{\tau_{3}}\right) \mathrm{d} t_{1} \\
& \doteqdot \frac{8}{15} \pi N_{0} D^{3 / 2} t^{3 / 2}\left\{1-\exp -\left(\frac{t}{\tau_{3}}\right)\right\} .
\end{aligned}
$$

The volume fraction of voids is

$$
\begin{aligned}
Y_{v} & =1-e^{-V_{\mathrm{e}}} \\
& =1-\exp \left\{-\left(\frac{t}{\tau_{2}}\right)^{3 / 2} \cdot\left[1-\exp -\left(\frac{t}{\tau_{3}}\right)\right]\right\},
\end{aligned}
$$

where

$$
\tau_{2}=\left(\frac{15}{8 \pi N_{0}}\right)^{2 / 3} \cdot \frac{1}{D} .
$$

Thus the equation in the bracket $\{\quad\}$ of eq. (36) has been derived. From the above, the two brackets $\{\quad\}$ in the eq. (36) express the formation (annihilation) of voids at time $t$. Deposition of $\mathrm{C}$ atoms from the cementite into the voids may take place and form graphite there. Therefore, the larger volume of voids makes possible the decomposition of larger amount of cementite. Thus the eq. (36) which expresses the amount of voids would determine the number of dissolving cementite particles. Further, $\lim _{t \rightarrow 0} N=\left(\tau_{5} \cdot \tau_{4}^{1.5}\right) /\left(\tau_{3} \cdot \tau_{2}^{1.5}\right) \neq 0$ due to the latter bracket \{\} in the eq. (36). This means that the pre-existing voids increase the number of dissolving cementite particles explosively.

Based upon the explanation of the eq. (36) mentioned above, the experimental results in the previous section can be understood as follows. The fluctuations of the time exponents $n_{2}$ and $n_{3}$ centering at about 1.5 correspond to the spherical shape of voids, and the temperature dependence of time constants $\tau_{2}$, $\tau_{3}$ comes from that of diffusion coefficient. Further, the tendency that the time exponents $n_{2}$ and $n_{3}$ become larger than 1.5 may result from the situation that the time exponent in the 2nd term or in the 4 th term becomes $1.5+\alpha$ if the exponents in the 3 rd or 5 th terms are expanded in Taylor's series when $\tau_{3}, \tau_{5} \gg t$. Namely the exponents act as a value larger than 1.5 in the low temperature annealing or at the early stage of annealing. The disappearance of effect of the second bracket $\{\quad\}$ in the eq. (36) when pre-annealed even if the specimen contains $\mathrm{Mg}$, may be due to the fact that the quenchedin voids formed by $\mathrm{Mg}$ are annihilated during annealing. In fact, it is confirmed by the metallographic observation that the spheroidizing ability of $\mathrm{Mg}$ disappears by the pre-annealing. The rough estimation of the time constant $\tau_{2}$ by the use of the eq. (42),

$$
\begin{aligned}
\tau_{2} & =\left(\frac{15}{8 \pi N_{0}}\right)^{2 / 3} \cdot \frac{1}{D}=\left[\frac{15}{8 \pi\left(1 / \frac{4}{3} \pi r^{3}\right)}\right]^{2 / 3} \cdot \frac{1}{D} \\
& \doteqdot r^{2} \frac{1}{D}
\end{aligned}
$$

gives $\tau_{2}=10^{3 \sim 4} \mathrm{~s}$, if the value of diffusion coefficient of $\mathrm{Fe}$ atom at $1250 \mathrm{~K}, D=3 \times 10^{-16}$ $5 \times 10^{-17} \mathrm{~m}^{2} / \mathrm{s}^{(22)}$ and the distance of voids (graphite), $r=3 \times 10^{-6} \mathrm{~m}$ are used. This agrees with the experimental value.

Finally, the new equation can be regarded as the generalized one of the $\mathrm{J}-\mathrm{M}$ equation, as pointed out previously. Therefore, the results obtained by the use of new equation is partly similar and partly dissimilar to those obtained by the J-M or A-R equations. The following may be said: The new equation has taken a step forward in that it reflects the complexity of real reactions more faithfully and, therefore, it can describe the whole process of graphitization of cementite more comprehensively and consistently and better agreements with experimental data have been achieved. 


\section{Conclusion}

A kinetic study of the process of graphitization of cementite was carried out by measuring the expansion of specimens during annealing. The following results were obtained.

(1) It has turned out clear in the kinetic studies based upon the Johnson-Mehl theory or the Austin-Rickett theory that the comprehensive and consistent analyses are impossible.

(2) Then it was tried to derive a new rate equation, and the following type of rate equation,

$$
\begin{aligned}
Y= & 1-\exp \left\{-\left(\frac{t}{\tau_{1}}\right)^{n_{1}}\left[1-\exp -\left(\frac{t}{\tau_{2}}\right)^{n_{2}}\right]\right. \\
& \left.\times\left[1-\exp -\left(\frac{t}{\tau_{3}}\right)^{n_{3}}\right]^{-1}\right\},
\end{aligned}
$$

was obtained.

(3) It has been clarified as the result of analyses based upon the new rate equation that main experimental results can be understood reasonably based upon the explanation that individual plate-like cementite decomposes by the interfacial reaction and the number of dissolving cementite particles is determined by the amount of voids.

\section{REFERENCES}

(1) J. Burke and W. S. Owen: J. Iron Steel Inst., 176 (1954), 196.

(2) C. E. Birchenall and H. W. Mead: J. Metals, N.Y., 8 (1956), 1004

(3) W. S. Owen: J. Iron Steel Inst., 182 (1956), 38.

(4) J. Burke: Acta Met., 7 (1959), 268.

(5) A. S. Appleton: J. Iron Steel Inst., 194 (1960), 160.

(6) J. Burke: J. Iron Inst., 194 (1960), 443.

(7) K. Pearce: M. Sc. Thesis. Victoria. Univ. Manchester, (1961).

(8) K. Pearce: J. Iron Steel Inst., 200 (1962), 28.

(9) K. Pearce and P. E. Evans: J. Iron Steel Inst., 203 (1965), 474.

(10) M. C. Ashton: AFS Cast Metal, 81 (1971), 18.

(11) J. W. Christian: The Theory of Transformations in Metals and Alloys, Pergamon Press, (1965), p. 472.

(12) J. Burke: The Kinetics of Phase Transformations in Metals, Pergamon Press, (1965), p. 192.

(13) S. Yamamoto: A Trial of $A$ New Reaction Rate Theory, Showado, (1979), p. 184.

(14) A. S. Appleton: J. Iron Steel Inst., 194 (1960), 160.

(15) M. C. Ashton: AFS Cast Metal, 82 (1972), 71.

(16) S. Yamamoto, T. Yasuda and Y. Murakami: J. Japan Inst. Metals, 41 (1977) 1194 (in Japanese).

(17) S. Yamamoto, B. Chang, Y. Kawano, R. Ozaki and Y. Murakami: Metal Science, 9 (1975), 360.

(18) Y. Li, Y. Kawano: J. Japan Inst. Metals, 44 (1980), 339 (in Japanese).

(19) K. Hanawa, K. Akechi, Z. Hara, T. Nakagawa: J. Japan Inst. Metals, 44 (1980), 943 (in Japanese).

(20) K. Hanawa, Z. Hara and K. Akechi: J. Japan Inst. Metals, 45 (1981), 438 (in Japanese).

(21) K. Akechi, W. A. Kaysser and G. Petzow: J. Japan Inst. Metals, 46 (1982), 330, 336 (in Japanese).

(22) Edited by Japan Inst. Metals: Metals Data Book, Maruzen, (1974). 